\title{
Theoretical and Methodical Aspects of Ensuring Sustainable Operation of the Businesses Considering Their Innovative Activity
}

\author{
Alexey Tikhonov ${ }^{1} \&$ Sergey Novikov ${ }^{1}$ \\ ${ }^{1}$ Moscow Aviation Institute (National Research University), Moscow, Russian Federation \\ Correspondence: Alexey Tikhonov, Moscow Aviation Institute (National Research University), Moscow, 4, \\ Volokolamskoe Highway, 125993, Russian Federation. Tel: 7-963-753-7110. E-mail: danonik92@mail.ru, \\ mai512hr@mail.ru
}

Received: April 22, 2020

Accepted: August 5, 2020

Online Published: September 3, 2020

doi:10.5430/rwe.v11n5p186

URL: https://doi.org/10.5430/rwe.v11n5p186

\begin{abstract}
This article considers a new approach to ensuring the sustainable functioning of a company considering its innovative activity on the basis of the original tools developed by the author, including strictly regulated indicators of the organization's activity, ensuring its stability, and their flexible filling to maintain it through a timely targeted impact on their level. The paper shows the interaction of two different levels of indicators in their quantitative and qualitative cross section.
\end{abstract}

Keywords: monitoring, signalling, management innovations, sustainable functioning, purposeful impact

\section{Introduction}

Tough competition, development of market economy in the Russian Federation in the conditions of dynamically developing external environment and other factors complicate functioning of the organizations. Their actual problem becomes maintenance of their stability and administrative innovative activity.

To this day, the existing management tools in the companies do not allow to fully form a harmonious relationship with the dynamism of the external environment. Often managerial innovations are not localized in the eyes of top managers. The potential of an organization, as a rule, is perceived by managers as technical and technological, which in general reduces the possibility for its dynamic development as a complex component mechanism, within which innovative management processes remain problem areas (Vorontsova \& Redkina, 2012).

Also, in the management area there is a tendency to focus exclusively on a limited number of indicators of the organization's activities, usually financial, which did not allow for a qualitative and comprehensive analysis of its real state, considering emerging threats, challenges, risks, etc. In this regard, it is difficult for organizations to maintain their ability to function sustainably over time, as it is achieved through the coordinated work of all their organizational and functional subsystems in all sections of the state of both internal and external environment.

Thus, it becomes important to outline a set of strategic tasks, the solution of which will allow the organization to adapt to its dynamically changing environment through the introduction of managerial innovations that correspond to the chosen direction of development of the company (Vorontsova, 2018).

\section{Literature Review}

Recently, there is a large number of new theoretical and methodological research works on the topic of increasing the competitiveness of organizations. Many authors consider advanced automation capabilities, analyze the use of new software products focused on the complex management of an organization's activities, from strategy to operational management (Boyer, 2010).

The authors Vorontsova, Y. V. (2018), Vorontsova, Y. V. \& Redkina, Y. S. (2012) were actively involved in the methodological aspects of management, concluding that the main factor in the competitiveness of a firm is to ensure the flexibility of the organization's functioning strategy. In the work of Pryanichnikov, S. B. (2018), the main emphasis was placed on the creation of information systems for continuous monitoring of sustainable innovative development of industrial enterprises. Nogovitsyna, O. S. (2015) scientifically proved that the innovative activity of an enterprise is the most important factor in ensuring its competitiveness in the market. Kosheleva, A. S. (2009) in her article investigated the issues of sustainable development and competitiveness of industrial enterprises, and special attention was paid to the study of theoretical, methodological and practical aspects of these concepts and their 
relationship and correlation. In the work of Borovskikh, N. V. \& Paskevich, E. V. (2017), the essence and process of ensuring the competitiveness of organizations were considered, specific measures were proposed to increase the competitiveness of a company at the present stage of economic development. The analysis of the competitiveness of organizations in The Global Competitiveness Report 2017-2018 (Schwab, 2017) was carried out according to 12 groups of indicators: higher education and training; market size; health care and primary education; technological readiness; efficiency of the goods market; innovation; infrastructure; business sophistication; labor market efficiency; financial market development; macroeconomic environment; institutions. In this work, the authors used these recommendations. The need to use modern information technologies that are actively developing in the era of the digital economy was substantiated in the work of Westerman, G. (2011). The authors in their article considered in detail the advantages and disadvantages of the Balanced Scorecard (BSC) system, previously proposed by Kaplan, R. \& Norton, D. (2003).

\section{Methodology}

We believe that due to the complexity of this problem, as well as the peculiarities of the external business environment, not all aspects of the conditions for the functioning of modern organizations, in particular dynamism, were previously taken into account by researchers from different countries when developing management systems for the sustainable functioning of organizations (Prahalad \& Ramaswamy, 2011). Study of such modern management tools as Management by Objectives (MBO), Management by Results (MBR), Tableau de Bord methodology, Total Performance Scorecard (TPS); Business Performance Management (BPM); Value Based Management (VBM); Hoshin planning, efficiency prism. and a number of others allowed us to conclude that there remained unresolved theoretical and practical problems associated with the issues of ensuring the flexibility of the system, making the sustainable functioning of the organization (Gates, 2009).

In general, the processes of development taking place in any organization are controlled by means of purposeful changes, deliberately introduced into its structure. However, it is quite difficult to predict the results of these changes, and therefore it is necessary to consider their unpredictability on a number of management actions in the future (Kraev \& Tikhonov, 2018). Therefore, there is a need to be guided by this position and to make measurements to determine the fluctuations in the values of the organization's performance indicators, which will characterize its stability. To consider such fluctuations, an original toolkit was developed, using the opportunity to influence the current situation in an organization through the formation of a set of indicators that allow it to be objectively assessed and, on this basis, to take timely proactive management actions to stabilize it (Akhmetshin, 2017).

\section{Results and Discussion}

For this purpose, it is proposed to consider a two-level set of indicators: indicators included in a rigid management circuit, and their components included in the so-called flexible filling. In addition, it is proposed to consider quantitative and qualitative indicators of the contours separately, as the tools used to track qualitative indicators require its integration with heuristic methods of their evaluation (Figure 1).

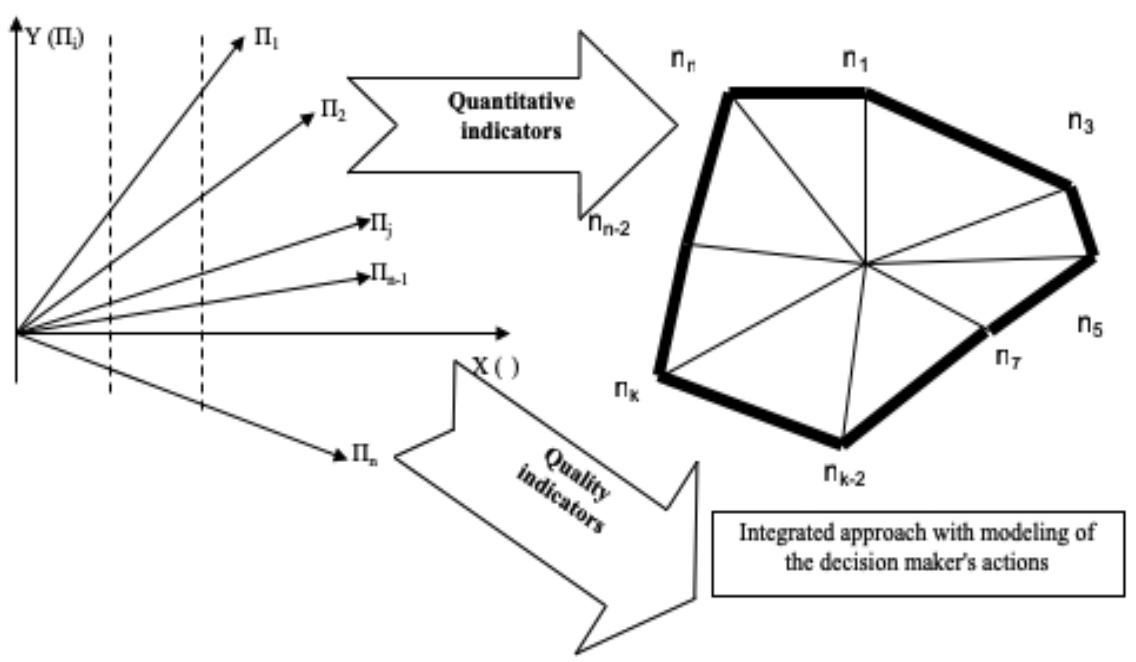

Figure 1. Working with a set of quantitative and qualitative indicators that form the stability of the organization in time 
In order to form an effective and efficient toolkit to ensure the sustainable functioning of the organization, it is necessary to understand the purpose of a rigid management framework of indicators and its flexible filling. The rigid administrative contour presupposes tracing of level of stability of the organisation in dynamic conditions of an environment, and the indicators forming its flexible filling are used for maintenance of its stability by means of an anticipatory signalling in a control system about dangerous deviations and-or approaching to admissible borders of indicators (Kraev, Tikhonov \& Novikov, 2018). The combination of rigid and flexible management circuits will ensure the stability of the organization's functioning over time through the development and implementation of timely managerial innovations, which will increase not only the competitiveness of the system itself, but also its development.

Determination of the overall sustainability of the organization can be viewed through a description of the function, depending on the indicators that will form a rigid contour and thus ensure sustainability over a given control horizon, as well as be adjusted during the control system setting process.

Sustainable functioning of the organization is also provided by managing indicators within each of the areas of functioning (Konovalov, Tikhonov, Fursov, Sogacheva \& Pyanova, 2017) (finance, sales, production, etc.), which can be identified in the construction of the system and adjusted depending on the state of the external environment of the organization, considering the emerging opportunities and threats, given the strengths and weaknesses of its internal environment (table).

Table 1. Iterative approach to the formation of the system of indicators tracking at any scale of calculations

\begin{tabular}{|c|c|c|c|}
\hline Type of iteration & $\begin{array}{c}\text { Rough } \\
\text { calculation }\end{array}$ & $\begin{array}{l}\text { Aggregated } \\
\text { (general) } \\
\text { calculation }\end{array}$ & $\begin{array}{c}\text { Detailed } \\
\text { calculation }\end{array}$ \\
\hline Defining of operation area & + & + & + \\
\hline $\begin{array}{l}\text { Formation of set of organizational performance } \\
\text { indicators }\end{array}$ & + & + & + \\
\hline $\begin{array}{l}\text { Formation of a "flexible" filler system of } \\
\text { monitored indicators }\end{array}$ & + & + & + \\
\hline $\begin{array}{l}\text { Graphical interpretation of the establishment of } \\
\text { relationships and interdependencies between } \\
\text { indicators within the scope of operation }\end{array}$ & & & + \\
\hline $\begin{array}{l}\text { Tabular representation of relationships and } \\
\text { interdependencies between indicators within the } \\
\text { operational area }\end{array}$ & & + & + \\
\hline $\begin{array}{l}\text { Performance evaluation of a strict outline of the } \\
\text { established criteria }\end{array}$ & & & + \\
\hline $\begin{array}{l}\text { Establishing relationships and interdependencies } \\
\text { between indicators of different areas of operation }\end{array}$ & + & & + \\
\hline $\begin{array}{l}\text { Establishing a close communication between } \\
\text { indicators of different areas of operation }\end{array}$ & & + & + \\
\hline $\begin{array}{l}\text { Assessment of the sensitivity between the tracked } \\
\text { indicators }\end{array}$ & & + & + \\
\hline $\begin{array}{l}\text { Formation of the target values of the monitored } \\
\text { parameters }\end{array}$ & + & + & + \\
\hline $\begin{array}{l}\text { Formation of the permissible tolerance values of } \\
\text { the indicators }\end{array}$ & + & + & + \\
\hline $\begin{array}{l}\text { Determination of frequency of calculation of } \\
\text { values of monitored indicators }\end{array}$ & + & + & + \\
\hline System detail & & & + \\
\hline
\end{tabular}

Indicators included in the rigid contour, as a rule, are monitored by organizations. They are a mandatory element of 
accounting (management, financial, etc.) and they form a stable functioning of the organization not only now, but also in the future (Kulikova, Smolentsev, Tikhonov, Kireev \& Dikareva, 2016). However, the indicators allocated to a rigid management circuit cannot be fixed at the strategic level, because their value depends on a number of factors, such as the technologies used in the organization, the organization of the production process, maintenance, etc (Nogovitsyna, 2015). The flexible filler can contain various norms and standards, on which the organization cannot initially affect. Therefore, even the "rigidity" of the management circuit can change, determining various reasonable deviations from the limits of indicators (Pryanichnikov, 2018). In this regard, the frequency of measurements (when tracking and adjusting) indicators of a rigid management circuit (liquidity ratios, financial condition, profitability, cost of production, etc.) will be determined either by the initially established periodicity or by sharp changes in the conditions of the external and internal environment of the organization in which it operates (Akhmetshin, Kuderova, Ryumshin, Gayazova, Romanova \& Erzinkyan, 2019).

In contrast to the indicators of a rigid management circuit, the indicators of a flexible one can vary both in their composition (which can be mobile) and in the degree of their influence on the indicators included in the rigid management circuit, according to the intensity of their change and the close relationship between them(Kogdenko, Melnik \& Bykovnikov, 2014).

The stability of the organization is determined by specific indicators, that is why the task of forming an effective tool to work with them is, first of all, to establish their composition, their normative-planned values and the boundaries of permissible deviations from them (Yurchenko \& Galyatkina, 2012). The conceptual scheme of the system of sustainable functioning of the organization is shown in the figure 2 . When building the system, it is recommended to consider that the composition of indicators may vary depending on the industry of the organization, its specifics, regional characteristics, etc.

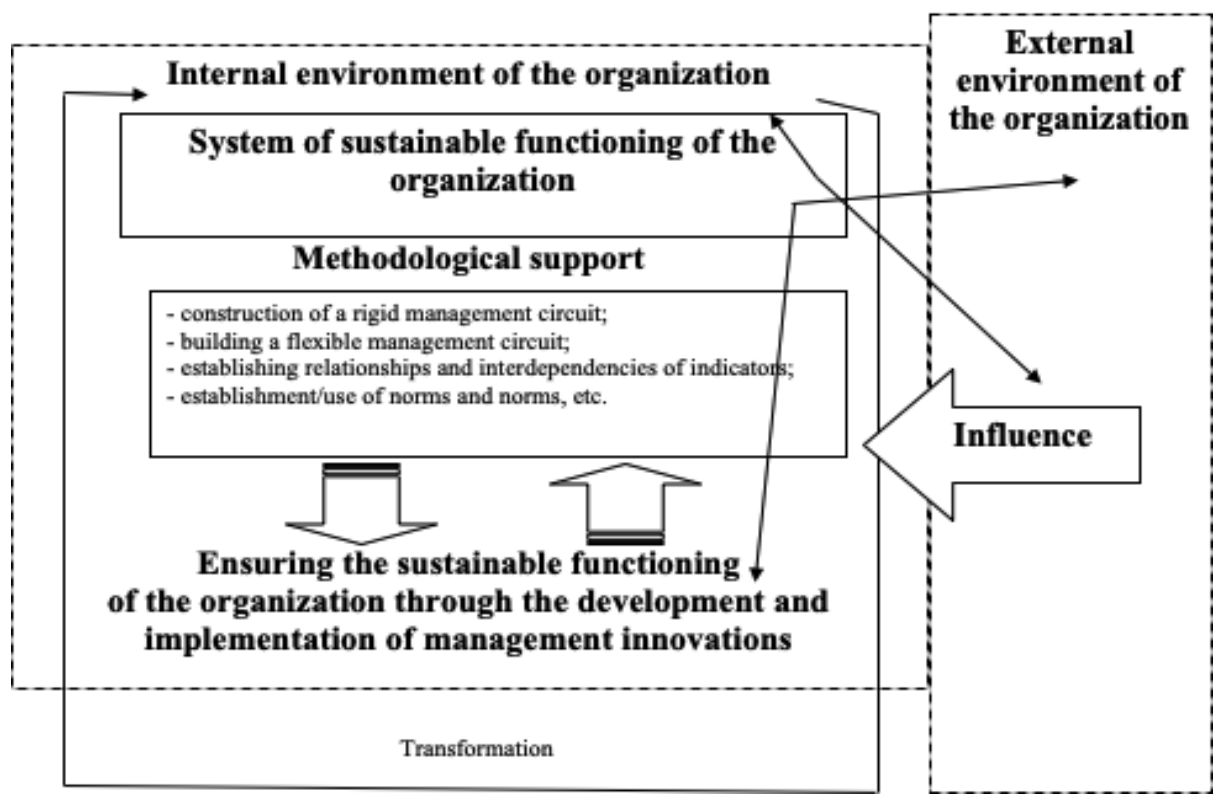

Figure 2. Conceptual framework for the sustainable functioning of the organization

System of monitor and built-in indicators must be in dynamic equilibrium with consideration of time factor. The preservation of optimal key economic characteristics of the system is guaranteed by the established analytical way of the relationship and interdependence between the indicators, united in a single complex by forming chains of cause-and-effect relationships (Konovalov, Tikhonov, Fursov, Sogacheva \& Pyanova, 2017).

At decomposition of the created system at the level of the organization to the functional and production divisions forming indicators of the rigid and flexible administrative contours their hierarchy allowing at various levels and considering change of the external and internal environment to adapt elements of the developed system to developing conditions that gives it the chance to remain actual is built (Fedotova, Tikhonov \& Novikov, 2018). At the same time, 
its dynamism is ensured by high-quality continuous monitoring and the possibility of timely adjustments to the indicators of a flexible management circuit. The position of the upper and lower boundaries of the contours can also change when the system is adjusted (Kraev \& Tikhonov, 2018).

The viability of the system to ensure the sustainable functioning of the organization is achieved:

- degree of flexibility of the system itself, the composition of its indicators, the ability to adapt to the current situation in the market, the ability to rebuild links both within the formed circuits and between them if there are threats in the internal and external environments;

- real-time monitoring of the situation;

- methodological tools that provide flexibility of the system (methods of determining the composition of indicators and their calculation, etc. are the methodological framework that allows to implement the concept of ensuring the sustainability of the organization).

\section{Conclusions}

The concept proposed by the author is focused on the formation and provision of sustainable operation of the organization on the basis of effective management of its state through a system of interrelated indicators monitored and controlled in the process of its adjustment to changes in the external environment.

The optimality of indicators of rigid and flexible management contours is achieved by the possibility of using deviations of values of indicators within the permissible limits, which are set by calculation, analytical, expert way or by integrating the methods considered. The range of variation of the controlled parameters can be used as a criterion of the system optimality. In a flexible management loop, it is possible to maneuver the composition of indicators, its components, which allows you to keep the values of indicators of a rigid management circuit within the permissible limits of their change. The criterion of optimality will determine the degree of stability of the system and its viability.

To ensure the sustainable functioning of the organization, it is necessary to carry out its diagnosis with a certain periodicity, which will allow to develop preventive management effects on the indicators included in the contours or to restrain their movement to the limits of the contours, or to change the boundaries of the contours themselves, which will characterize the exit of the organization to a new level of its development.

In some cases, changes in the boundaries of the contours will affect only the indicators of the flexible management circuit, without affecting the indicators included in the rigid management circuit. It will manifest the dynamism of the system of sustainable functioning of the organization and its resistance to negative factors of the environment. Purposefully working on the elements of the system, the organization has the ability to adjust the direction and intensity of development, the growth rate of its functioning that provides the basis for modeling organizational processes in your organization to ensure its sustainability over time (considering its dynamism).

Organizations focused only on their own survival are not engaged in the search and implementation of innovations and solve their acute immediate specific problems. However, in a dynamic business environment, it is necessary to be able to predict changes both negative and positive, using, for example, a scenario approach and to be able to develop and implement management innovations that will provide flexibility of management and the ability to adapt to a dynamically changing environment.

The use of the system of sustainable functioning of the organization will ensure the timeliness of the development of various innovative programs and the adoption of innovative and active management decisions, thus providing innovative activity in the field of management technologies with the ability to maintain the sustainable functioning of the organization.

\section{References}

Akhmetshin, E. M. (2017). The System of Internal Control as a Factor in the Integration of the Strategic and Innovation Dimensions of a Company's Development. Journal of Advanced Research in Law and Economics, $8(6), 1684-1692$.

Akhmetshin, E. M., Kuderova, I. G., Ryumshin, A. V., Gayazova, S. R., Romanova, E. V., \& Erzinkyan, E. A. (2019). Entrepreneurial skills development through distance learning. Journal of Entrepreneurship Education, 22, 1-12.

Borovskikh, N. V., \& Paskevich, E. V. (2017). Ensuring the competitiveness of the enterprise. Young scientist, 3(137), 299-302.

Boyer, J. (2010). Business Intelligence Strategy. A Practical Guide for Achieving BI Excellence. Ketchum: MC Press Online. 
Fedotova, M. A., Tikhonov, A. I., \& Novikov, S. V. (2018). Estimating the effectiveness of personnel management at aviation enterprises. Russian Engineering Research, 38(6), 466-468.

Gates, W. H. (2009). Business at the Speed of Thought. Harlow: Pearson Education.

Kaplan, R., \& Norton, D. (2003). Balanced Scorecard: From Strategy to Action. Moscow: JSC "Olympus-Business".

Kogdenko, V. G., Melnik, M. V., \& Bykovnikov, I. L. (2014). Company value management. Textbook. Moscow: Unity-Dana.

Konovalov, V. B., Tikhonov, A. I., Fursov, V. A., Sogacheva, O. V., \& Pyanova, N. V. (2017). Marketing planning in industrial enterprises in the context of import substitution strategy. International Journal of Applied Business and Economic Research, 15(12), 171-182.

Kosheleva, A. S. (2009). Competitiveness and sustainable development of an industrial enterprise. Bulletin of the Saratov State Social and Economic University, 5, 4-9.

Kraev, V. M., \& Tikhonov, A. I. (2018). Conversion of low-thrust airplane gas-turbine engines to power generators. Russian Engineering Research, 38(7), 536-539.

Kraev, V. M., \& Tikhonov, A. I. (2018). Gas-Turbines and the Competitiveness of Aviation Plants. Russian Engineering Research, 38(4), 288-290.

Kraev, V. M., Tikhonov, A. I., \& Novikov, S. V. (2018). Economic Conversion in the Aviation Industry. Russian Engineering Research, 38(4), 330-333.

Kulikova, N. N., Smolentsev, V. M., Tikhonov, A. I., Kireev, V. S., \& Dikareva, V. A. (2016). Planning of technological development of new products and its impact on the economic performance of the enterprise. International Journal of Economics and Financial Issues, 6(8), 213-219.

Nogovitsyna, O. S. (2015). Innovative activity as a factor of a company's sustainability on the market. Polythematic Network Electronic Scientific Journal of the Kuban State Agrarian University, 110, 1157-1166.

Prahalad, C. K., \& Ramaswamy, V. (2011). The Future of competition: Creating unique value with consumers. Moscow: JSC "Olympus-Business".

Pryanichnikov, S. B. (2018). Formation of monitoring system for sustainable innovative development of industrial enterprises. Economics and Entrepreneurship, 1(90), 903-907.

Schwab, K. (2017). The Global Competitiveness Report 2017-2018. Retrieved from http://www3.weforum.org/docs/GCR2017-2018/05FullReport/TheGlobalCompetitivenessReport2017-2018.pdf

Vorontsova, Y. V., \& Redkina, Y. S. (2012). Ensuring the flexibility of the strategy of the organization as a factor of its competitiveness. Bulletin of the University, 11, 175-180.

Vorontsova, Y. V. (2018). Methodical aspects of the industrial business value management. Bulletin of the University, $11,11-17$.

Westerman, G. (2011). Digital Transformation: A Road-Map for Billion-Dollar Organizations. MIT Center for Digital Business and Capgemini Consulting, 1-68.

Yurchenko, T. I., \& Galyatkina, O. N. (2012). Tools to ensure the sustainable functioning of the organization. Bulletin of the University, 11, 215-221.

\section{Copyrights}

Copyright for this article is retained by the author(s), with first publication rights granted to the journal.

This is an open-access article distributed under the terms and conditions of the Creative Commons Attribution license (http://creativecommons.org/licenses/by/4.0/). 